\title{
O CONCEITO DE DEFESA SOCIAL E SEGURANÇA PÚBLICA NA ORDEM DEMOCRÁTICA BRASILEIRA
}

\author{
THE CONCEPT OF SOCIAL DEFENSE AND PUBLIC SECURITY IN THE \\ BRAZILIAN DEMOCRATIC ORDER
}

Bartira Macedo de Miranda ${ }^{1}$

Franciele Silva Cardoso ${ }^{2}$

\begin{abstract}
Resumo: As formulações teóricas que possibilitaram a construção das ideias de defesa social possuem várias vertentes e chegam a constituir ideias contraditórias designadas pela mesma expressão "defesa social". As ideias de defesa social começaram a ser difundidas no Brasil a partir do ano de 1884, pelas Faculdades de Direito de Recife e São Paulo, e foram amplamente adotadas na legislação penal com a edição do Código Penal de 1940 e o Código de Processo Penal de 1941. Hoje em dia o discurso de defesa social se encontra difuso e se articula em torno de uma concepção de direito penal do autor (tomando os etiquetados de criminosos como inimigos da sociedade e que precisam ser combatidos), e em nome desta defesa social, justificam-se toda sorte de violações dos direitos humanos, que marcam a segurança pública no Brasil. Não raro, as violações dos direitos humanos estão acompanhadas de um discurso justificador que invoca a necessidade de defesa social no combate ao crime. Este artigo busca compreender o conceito de defesa social e segurança pública, com suas ramificações teóricas e questões ideológicas que os permeiam. Busca-se traçar o caminho teórico percorrido na formulação dos conceitos e refletir o que se pode entender por defesa social e segurança pública na ordem democrática vigente no Brasil, neste início de século XXI.
\end{abstract}

Palavras-chave: Defesa Social; Segurança Pública; Políticas de Segurança; Sistema de Justiça; Política Criminal.

\begin{abstract}
The theoretical formulations that enabled the construction of social defense ideas have several aspects and even constitute contradictory ideas designated by the same expression "social defense". The ideas of social defense began to be disseminated in Brazil in 1884, by the Law Schools of Recife and São Paulo, and were widely adopted in penal legislation with the edition of the 1940 Penal Code and the Criminal Procedure Code of 1941. Nowadays the social defense discourse is diffuse and articulates around a conception of criminal law of the author (taking the labeled criminals as enemies of society and that need to be fought), and in the name of this social defense, all sorts of human rights violations, which mark public security in Brazil, are justified. Not infrequently, human rights violations are accompanied by a justifying discourse that invokes the need for social defense in the fight against crime. This article seeks to understand the concept of social defense and public security, with its theoretical ramifications and ideological issues that permeate them. It seeks to trace the theoretical path taken in the formulation of concepts and reflect what can be understood by social defense and public security in the democratic order in force in Brazil, at the beginning of the 21 st century.
\end{abstract}

Keywords: Social Defense; Public security; Security Policies; Justice system; Criminal Policy.

\footnotetext{
1 Doutora em História da Ciência, Professora e bolsista produtividade do Programa de Pós-Graduação em Direito e Políticas Públicas e Diretora da Faculdade de Direito da Universidade Federal de Goiás. Atualmente é Diretora da Faculdade de Direito da UFG e Conselheira Seccional da OAB-GO. E-mail: bartiraufg@gmail.com 2 Doutora e Mestre em Direito Penal e Criminologia pela Universidade de São Paulo, Professora e bolsista produtividade do Programa de Pós-Graduação em Direito e Políticas Públicas. E-mail: francielecardoso@gmail.com
} 


\section{INTRODUÇÃO}

A área da segurança pública mudou muito nos últimos vinte anos. Porém, apesar dos avanços, a segurança pública ainda é um conceito em aberto. Mesmo após o processo de democratização que culminou na Constituição Federal de 1988, a segurança pública continua reproduzindo práticas, saberes e teorias que serviam aos governos ditatoriais e não consegue ser pensada para além da gestão das polícias e da lógica do direito penal.

A defesa social é uma ideia que assume diferentes significados no decorrer dos tempos e, em determinados momentos, chega a configurar conceitos contraditórios se o compararmos nas múltiplas roupagens em que aparece nas diferentes escolas científicas, mas é também, ao mesmo tempo, um nó teórico que permeia a ciência penal na medida em que se apresenta como uma poderosa justificação do poder punitivo, seja em sua face jurídica (com seus discursos presentes nos processos judiciais), seja na face não-jurídica (dos discursos dos agentes e sujeitos da segurança pública, da mídia e da população.

O sistema penal brasileiro, irradiado pela ideologia da defesa social, em certa medida, tem se configurado como um instrumento de controle social para a exclusão de pessoas indesejadas (negros, pobres, perigosos, degenerados), em detrimento de um sistema jurídico voltado para a punição de condutas criminosas.

No âmbito da segurança pública, as ideias de defesa social também constituem um empecilho epistemológico, na medida em que dificultam a elaboração e implantação de políticas públicas de segurança. Enquanto se pensa a segurança pública em termos de guerra, não se desenvolvem políticas de redução da violência.

No Brasil, a defesa social se tornou sinônimo de segurança pública? Este artigo busca compreender o conceito de defesa social e segurança pública, com suas ramificações teóricas e questões ideológicas que os permeiam. Busca-se traçar o caminho teórico percorrido na formulação dos conceitos e refletir o que se pode entender por defesa social e segurança pública na ordem democrática vigente no Brasil, neste início de século XXI.

\section{O PERCURSO TEÓRICO DO CONCEITO DE DEFESA SOCIAL}

Para Marc Ancel (1979; p.2-3), a defesa social é frequentemente identificada como "proteção da sociedade contra o crime, na medida em que se procura obter essa proteção através de uma repressão vigorosa das infrações cometidas". Este é o conceito mais comum para o termo "defesa social”. Quando se utiliza a expressão "defesa social” ou "defesa da sociedade", quase sempre está-se referindo a um conjunto de ideias e medidas justificadoras de um rigoroso modelo punitivo.

Mas, a defesa social não é um termo unívoco.

Os clássicos ${ }^{3}$ (Carrara, por exemplo) entendiam a defesa social como a proteção que a sociedade deve fazer ao indivíduo contra os arbítrios do poder punitivo. Por outro lado, os Positivistas

3 Aqui nos referimos aos teóricos da chamada Escola Clássica do Direito Penal, que se dedicaram a estabelecer limites ao poder punitivo, na Europa do século XVIII. 
(principalmente Ferri) entendiam que o Estado tem o legítimo direito de defender a sociedade contra os criminosos e com suas teorias justificavam a ampliação do poder punitivo.

A escola positiva ${ }^{4}$ colocou o termo defesa social no centro do debate penal, eis que em seus postulados fundamentais justificava o sistema punitivo na necessidade de defender a sociedade contra o crime e os criminosos, fazendo o direito penal se desprender do julgamento do fato-crime, para "tratar"/julgar os indivíduos (de acordo com a sua periculosidade), num autêntico "direito penal do autor". Nesse diapasão, a pena, por exemplo, será vista como um instrumento de defesa social, utilizável para a eliminação dos indivíduos indesejados (perigosos). Defendendo maior repressão penal, a Escola Positiva foi a grande precursora das ideias de defesa social e suas concepções foram amplamente difundidas no Século XX, na América Latina. Os Estados Unidos exerceu forte protagonismo na divulgação e exportação dessas ideias.

Assim as ideias de defesa social vão desde concepções de proteção dos direitos dos indivíduos até a eliminação e supressão das próprias garantias e direitos individuais, em nome da eficácia da defesa social na proteção da sociedade, culminando com a proposta de eliminação do próprio direito penal e do sistema de justiça criminal, para em seu lugar criar-se um novo "direito de defesa social"s.

Na Europa, com a especialização dos saberes e a divisão das ciências penais operada principalmente por Liszt, no início do século XX, os partidários da defesa social se organizaram em torno da Associação Internacional de Direito Penal. A partir daí, as concepções de defesa social foram se constituindo como um conjunto autônomo de ideias com pretensões científicas e tentaram formar um novo campo de pesquisa, voltado especificamente para o combate ao crime (centrado na contenção dos indivíduos considerados perigosos). A partir daí, os postulados da defesa social foram incorporados pela legislação de vários países, deixando de ser uma discussão de política criminal para se constituir num debate acerca da interpretação legal. Assim, pode-se dizer que a Escola Técnico-jurídica, ao promover a divisão dos saberes penais, expulsou a defesa social do campo do direito penal, mas ela saiu pela porta e entrou pela janela. Uma vez adotada pela legislação, ela voltou ao campo penal, passando a ser uma discussão dogmática, de mera aplicação e interpretação literal da lei.

Conforme explana Francisco Munhoz Conde, os penalistas não quiseram ou não souberam ver as consequências do cultivo dessa dogmática jurídico-penal l'art pour l'art, afastando-se bastante da realidade política, social e econômica da época, deixando "a porta aberta à terrível besta do nacional socialismo" (CONDE; p. 30) como verdadeiro inimigo da dignidade humana.

O direito penal cultivado na República de Weimar, período que vai do fim da Primeira Guerra Mundial até o início do regime nazista, compreendido entre os anos de 1918 e 1944, na Alemanha, é o exemplo mais emblemático de como os discursos punitivos se expandem quando o direito penal falha na sua função de impor limites ao poder punitivo, culminando em massacres. Depois que o direito penal foi desprendido do fato, por obra dos positivistas, e toda construção teórica do

4 Por escola positiva entende-se o movimento antropológico e positivista que surgiu no final do século XIX, na Itália, com os trabalhos de Lombroso, Ferri e Garofalo.

5 Segundo Gramatica, citado por Marc Ancel, um 'direito de defesa social' deve substituir o direito penal existente; pois esse direito de defesa social se atribui como finalidade a adaptação do indivíduo à ordem social e não a sanção de seus atos. (ANCEL: 1979; p. 124) 
início do século XX, pela qual a pena deveria ser uma medida de defesa social e se adequar à personalidade do criminoso, não foi difícil, para os teóricos do nacional-socialismo, como Edmundo Mezger (ANCEL: 1979; p. 81), defender que a pena deve ser também a "eliminação dos elementos daninhos ao povo e à raça", e propor "medidas de higiene racial para a eliminação das ralés criminosas", pois a raça "determina não só diretamente a forma de delinquir do sujeito, mas também toda a sua atitude social dentro da comunidade".

Para Mezger (ANCEL: 1979; p. 89), a justiça penal deveria colocar-se "a serviço da regeneração do povo" e propôs todo um programa de "limpeza étnica", que foi levado às últimas consequências com a política de extermínio dos elementos indesejáveis, inimigos do povo ou estranhos a comunidade, a dizer, mendigos, vagabundos (desempregados), ciganos, deficientes físicos, homossexuais, testemunhas de Jeová, comunistas e "outra gente da mesma laia", como se dizia frequentemente na terminologia nazista da época. Entre 1930 e 1940 houve um aumento vertiginoso de fatos puníveis e várias leis foram se sucedendo para excluir os judeus da sociedade civil.

Estima-se que o regime nazista levou à morte seis milhões de judeus, chegando a 11 milhões de mortos, considerando os civis e prisioneiros de guerra. Vemos no direito penal nazista o desdobramento das ideias iniciadas pela escola positiva italiana e cultivada no saber penal do início do século XX pelos partidários da defesa social, embora não se possa dizer que estes tiveram atuação direta na política genocida do Terceiro Reich. Marc Ancel chega a dizer que durante o entre guerras houve um eclipse nas ideias de defesa social. No entanto, a política de extermínio e o holocausto são exemplos de onde podemos chegar quando o direito penal perde os freios que lhe prendem ao fato-crime e à legalidade dos delitos e das penas, vale dizer, quando o direito penal do fato é substituído ao direito penal do autor.

Após a Segunda Guerra Mundial, os partidários da defesa social voltaram a se organizar. Filippo Gramatica fundou o Centro de Estudos de Defesa Social em 1945, em Gênova. O $1^{\circ}$ Congresso Internacional de Defesa Social foi realizado em 1947. A Sociedade Internacional de Defesa Social foi fundada em 1949. Em 1950 foi criado o Departamento de Defesa Social das Nações Unidas. Em 1953, se constitui, na órbita do Instituto de Direito Comparado da Universidade de Paris, um Centro de Estudos de Defesa Social. Com tudo isso, o movimento de defesa social foi ganhando grande prestígio.

As ideias defendidas pelo movimento sempre estiveram impregnadas da negação aos princípios da legalidade dos delitos e das penas, embora seu discurso se apresente envernizado com uma posição contraria à repressão e à punição. É que para punir exige-se a prática de um crime. Então, para punir sem crime era preciso criar outra nomenclatura e outra lógica para a justiça criminal, onde o sujeito não seria julgado pelo fato-crime praticado, mas de acordo com a "periculosidade", "temibilidade" ou "anti-socialidade" de sua personalidade. Veja-se, a propósito o pensamento de Filippo Gramatica, citado por Marc Ancel:

Gramática pretende deduzir então, que o direito de defesa social postula a abolição da responsabilidade penal e a substituição dessa responsabilidade penal pela noção de anti-socialidade. A doutrina comporta igualmente a exclusão do problema filosófico da liberdade, e sobretudo, de forma mais direta, a rejeição das noções de delito e de pena. As "medidas de defesa social" em substituição à pena têm por base o conhecimento da personalidade do infrator. 
Porém, a partir do III Congresso Internacional de Defesa Social, realizado em Anvers em 1954, passou-se a distinguir duas tendências divergentes no movimento: uma posição extremada, representada pelas ideias de Gramatica, que buscava a eliminação do direito penal; outra, de posição moderada ou reformista, liderada por Marc Ancel, que pretendia adaptar a defesa social ao direito penal vigente.

Do debate entre essas duas posições, foi elaborado um Programa mínimo, saindo vencedora a posição moderada, representada por Marc Ancel. O próprio Gramatica aderiu ao programa mínimo, com ressalva de suas posições pessoais, o que fez com que o movimento mantivesse a sua unidade e coesão.

As posições de Marc Ancel são menos radicais do que as de Gramatica, mas não deixam de estarem contrárias ao sistema de legalidade dos delitos e das penas, pois um de seus postulados fundamentais diz respeito à "luta contra o juridismo" e ao "dogmatismo". Marc Ancel continuava vendo o crime como uma manifestação da personalidade de seu autor e a pena, para ele, deveria ter por função a ressocialização ou reforma do condenado, defendendo, com isso, as penas indeterminadas pelas quais, o condenado deveria permanecer preso até ser corrigido ou "curado".

\section{AS CONCEPÇÕES CONTEMPORÂNEAS ACERCA DA DEFESA SOCIAL E SEGURANÇA PÚBLICA NO BRASIL}

Conforme demonstrado, as formulações teóricas que possibilitaram a construção das ideias de defesa social possuem várias vertentes e chegam a constituir ideias contraditórias designadas pela mesma expressão "defesa social”. A confusão é tanta que Jimenez Asúa, um dos mais destacados criminalistas do Século XX, chegou a afirmar, em 1958, que "ninguém sabe hoje o que é defesa social".

As ideias de defesa social começaram a ser difundidas no Brasil a partir do ano de 1884, pelas Faculdades de Direito de Recife e São Paulo, e foram amplamente adotadas na legislação penal com a edição do Código Penal de 1940 e o Código de Processo Penal de 1941.

Marcos Cesar Alvarez explica que o discurso de defesa social que aparece no interior do saber penal, no Brasil, representou a emergência de um discurso da desigualdade no campo da lei, que foi capaz de propor um tratamento jurídico-penal diferenciado para determinados setores da população e, consequentemente, num plano mais geral, de estabelecer critérios diferenciados de cidadania. (ANCEL: 1979; p. 32-33)

O positivismo criminológico que se desenvolveu no Brasil forneceu todo um arcabouço argumentativo para criminalizar determinadas pessoas, e o sistema punitivo foi direcionado a punir determinados indivíduos rotulados de perigosos (criminosos), mais do que condutas criminosas (perigosas).

São elucidativas as palavras de Noé de Azevedo:

O que o novo direito penal tem em vista é a defesa da sociedade contra a ação de indivíduos perigosos. Pouco importa que eles tenham delinquido ou não; desde que se revele por qualquer modo a periculosidade, deve o Estado tomar as necessárias medidas de prevenção, dando aos indivíduos perigosos o tratamento adequado para evitar que venham a causar dano a seus semelhantes. (AZEVEDO: 1936; p. 7) 
Assim, os discursos penais nas primeiras décadas do século XX, no Brasil, caracterizam-se pela negação de direitos de cidadania às classes sociais desprovidas de menos poder, estabelecendo uma cultura antidemocrática e repressora, ao mesmo tempo em que protegia o patrimônio e as classes sociais mais altas.

Hoje em dia o discurso de defesa social se encontra difuso e se articula em torno de uma concepção de direito penal do autor (tomando os etiquetados de criminosos como inimigos da sociedade e que precisam ser combatidos), e em nome desta defesa social, justificam-se toda sorte de violações dos direitos humanos, que marcam a segurança pública no Brasil. Não raro, as violações dos direitos humanos estão acompanhadas de um discurso justificador que invoca a necessidade de defesa social no combate ao crime ${ }^{6}$.

A ideia de defesa social se estrutura em uma concepção guerreira da sociedade, pois pressupõe a proteção de alguns indivíduos (as pessoas de bem) contra outros (os criminosos, perigosos etc). Trata-se de uma concepção incompatível com os pressupostos de um Estado democrático de direito. Também é comum o emprego da expressão "defesa social” para designar a defesa do Estado contra o indivíduo, concepção que aniquila o ser humano como sujeito de direito.

Como se vê, as concepções de defesa social são ideologias propícias aos estados autoritários, que privilegiam a autoridade governamental, concentrando o poder político nas mãos de uma só pessoa ou grupo.

Nas últimas décadas, no Brasil, a defesa social se aproxima da "Segurança Pública", haja vista a denominação adotada por vários estados e alguns municípios, cada um com a sua "Secretaria de Defesa Social"7. Muitas dessas secretarias, no entanto, adotaram essa denominação ora para indicar uma nova concepção de segurança pública que respeita os direitos humanos, ora simplesmente por não poderem adotar a denominação de "secretaria de segurança pública", no caso dos municípios, haja vista que a segurança pública é da competência dos estados.

No site do Ministério da Justiça (2015; online), a defesa social é definida como "a prestação de serviços de segurança pública e de defesa civil, entre outras atividades”.

Já o termo segurança pública, por sua vez, no mesmo site, é definida como "uma atividade pertinente aos órgãos estatais e à comunidade como um todo, realizada com o fito de proteger a cidadania, prevenindo e controlando manifestações da criminalidade e da violência, efetivas ou potenciais, garantindo o exercício pleno da cidadania nos limites da lei”.

\section{A SEGURANÇA PÚBLICA NA CONSTITUIÇÃO FEDERAL DE 1988}

6 A título de exemplo, citamos o discurso do Governador da Bahia, Rui Costa, que logo após o massacre que ficou conhecido como a Chacina do Cabula, em janeiro de 2015, defendendo os policiais militares que mataram 12 jovens na periferia de salvador, indagado após relatório da Anistia Internacional que enquadrava o fato como execução sumária, afirmou simplesmente: "Continuo com a postura de presunção da inocência das pessoas que estiverem atuando em defesa da sociedade”. In: http://www.correio24horas.com.br/detalhe/noticia/morte-de-12-homens-no-cabula-foi-execucao-diz-mp-policiais-serao-denunciados/?cHash=9cc0567b569bdbe83b2aa06242ec07f5, Acesso em: 27 jul. 2015.

7 São exemplos de estados que criaram "secretaria de defesa social" ao invés de "secretaria de segurança pública": Pernambuco, Alagoas e Minas Gerais. Outros adotam a expressão "Secretaria de Estado de Defesa Social e Segurança Pública", como Paraíba e Ceará. 
Há basicamente duas concepções que rivalizam o conceito de segurança pública no Brasil: uma centrada na ideia de guerra e combate; outra, na prestação de serviço público, por meio de políticas públicas de segurança.

A primeira concepção acerca do conceito de segurança pública concebe a missão institucional das polícias em termos bélicos e está assim descrita por Cláudio Pereira de Souza Neto (2008; p. 3):

Seu papel é "combater" os criminosos, que são convertidos em "inimigos internos". As
favelas são "territórios hostis", que precisam ser "ocupados" através da utilização do "poder
militar". A política de segurança é formulada como "estratégia de guerra". E, na "guerra",
medidas excepcionais se justificam. Instaura-se, então "uma política de segurança de
emergência" e um "direito penal do inimigo". O "inimigo interno" anterior - o comunista
- é substituído pelo "traficante", como elemento de justificação do recrudescimento das
estratégias bélicas de controle social.

Esse modelo é reminiscente do regime militar, e, há décadas, tem sido naturalizado como o único que se encontra à disposição dos governos, não obstante sua incompatibilidade com a ordem constitucional brasileira. O modelo tem resistido pela via da impermeabilidade das corporações policiais, do populismo autoritário de sucessivos governos e do discurso hegemônico dos meios de comunicação social. (SOUZA NETO: 2008; p. 5)

A segunda concepção está centrada na ideia de que a segurança é "um serviço público" a ser prestado pelo Estado:

O cidadão é o destinatário desse serviço. Não há mais "inimigo" a combater, mas cidadãos para servir. A polícia democrática, prestadora de serviço público, em regra, é uma polícia civil, embora possa atuar uniformizada, sobretudo no policiamento ostensivo. A polícia democrática não discrimina, não faz distinções arbitrárias: trata os barracos nas favelas como "domicílios invioláveis", respeita os direitos individuais, independentemente de classe, etnia ou orientação sexual; não só se atém aos limites inerentes ao Estado democrático de direito, como entende que seu principal papel é promove-lo. A concepção democrática estimula a participação popular na gestão da segurança pública; valoriza arranjos participativos e incrementa a transparência das instituições policiais. (SOUZA NETO: 2008; p. 6)

Nesta concepção de segurança, o combate militar é substituído pela prevenção, pela integração com políticas sociais, por medidas administrativas de redução dos riscos e pela ênfase na investigação criminal. (SOUZA NETO: 2008; p. 6-7)

A Constituição Federal não optou, com a precisão desejável, nem por um nem por outro modelo, pois, por um lado, concebeu como finalidade das políticas de segurança a preservação da “incolumidade das pessoas e do patrimônio". Por outro lado, manteve parte importante da polícia militarizada, eis que, embora subordinadas aos governadores dos estados, as polícias militares continuam previstas como "forças auxiliares e reservas do Exército" (Art. 144, § 5).

Além do mais, a Constituição está repleta de conceitos imprecisos. É o caso do de "ordem pública", que pode ser mobilizado, de acordo com as circunstâncias para justificar um ou outro tipo de intervenção policial. Contudo, essa ambiguidade não autoriza dizer que a Constituição autoriza tanto práticas autoritárias quanto democráticas.

Um conceito de segurança pública adequado à Constituição de 1988 é um conceito que se harmonize com o princípio democrático, com os direitos fundamentais e com a dignidade da pes- 
soa humana. Por essa razão, apenas as políticas de segurança pública alicerçadas em concepções democráticas, comprometidas com a observância efetiva desses princípios, são compatíveis com a Constituição Federal. (SOUZA NETO: 2008; p. 8-9)

$\mathrm{O}$ art. $5^{\circ}$ da Constituição Federal eleva a segurança pública à condição de direito fundamental:

Art. $5^{\circ}$ Todos são iguais perante a lei, sem distinção de qualquer natureza, garantindo-se aos brasileiros e aos estrangeiros residentes no País a inviolabilidade do direito à vida, à liberdade, à igualdade, à segurança e à propriedade.

A segurança é um direito básico que deve ser universalizado, como os outros direitos fundamentais. A segurança é direito de todos. O programa constitucional nos impõe a superação da tendência atual de se conceber parte da população como a que merece proteção - as classes médias e altas - e parte como a que deve ser reprimida - os excluídos, os negros, os habitantes das favelas. (SOUZA NETO: 2008; p. 10) Afinal, a Constituição também prevê a segurança como um direito social:

Art. $6^{\circ}$ São direitos sociais a educação, a saúde, a alimentação, o trabalho, a moradia, o transporte, o lazer, a segurança, a previdência social, a proteção à maternidade e à infância, a assistência aos desamparados, na forma desta Constituição.

Mas é no art. 144, que a Constituição estrutura a segurança pública, em capítulo específico:

\section{DA SEGURANÇA PÚBLICA}

Art. 144. A segurança pública, dever do Estado, direito e responsabilidade de todos, é exercida para a preservação da ordem pública e da incolumidade das pessoas e do patrimônio, através dos seguintes órgãos:

I - polícia federal;

II - polícia rodoviária federal;

III - polícia ferroviária federal;

IV - polícias civis;

V - polícias militares e corpos de bombeiros militares.

Ao mesmo tempo que é um direito fundamental individual, a segurança pública é um dever do Estado e será exercida para a preservação da ordem pública e também preservar a incolumidade das pessoas e do patrimônio.

O uso da expressão "ordem pública", que é um conceito jurídico indeterminado, abre-se a diferentes apropriações, democráticas e autoritárias, comprometidas ou não com o respeito ao estado democrático de direito e com a preservação da legalidade. (SOUZA NETO: 2008; p. 12) A lei é muitas vezes entendida como um entrave à garantia da ordem pública; e os direitos humanos, como obstáculos à atuação eficiente das autoridades policiais. (SOUZA NETO: 2008; p. 13)

Porém, uma ordem pública democrática é aquela estruturada pela Constituição e pelas leis. Preservar a ordem pública significa, sobretudo, preservar o direito, a ordem juridicamente estruturada, garantir a legalidade. 


\section{A PERSISTÊNCIA DO CARÁTER AUTORITÁRIO DA SEGURANÇA PÚBLICA BRASILEIRA}

A restabelecimento do Estado democrático não foi suficiente para conter os arbítrios das agências responsáveis pela segurança e ordem pública.

No campo prático, ainda se vive um Estado autoritário no Brasil, principalmente nas questões relacionadas à segurança pública, pois o processo de democratização pouco modificou o Estado repressivo e penalizador.

A penalização é utilizada como forma de se ampliar o controle sobre as periferias, manter a ordem pública e a enorme desigualdade social.

Temos, assim, no Brasil, um "Estado para os pobres", com menos assistência e mais controle e vigilância, e um "Estado para os ricos", que possibilita menos controle sobre a reprodução econômica e multiplicação do lucro. Acaba-se tendo "menos Estado" para os ricos e "mais Estado Penal" para os pobres. O Estado serve, assim, aos poucos "donos do poder" em detrimento da soberania do povo. (CARVALHO; SILVA: 2011; p. 60)

As políticas de segurança pública e justiça criminal adotados pelos governos democráticos não se diferenciaram daquelas adotadas pelo regime autoritário ${ }^{8}$.

\footnotetext{
O legado autoritário aparece claramente nas práticas ilegais e no uso indiscriminado da violência por parte dos aparelhos repressivos. Corrobora com este fato a formação policial com lacunas profundas no campo dos direitos humanos e no respeito à cidadania. $\mathrm{O}$ uso da tortura nas batidas policiais e nos interrogatórios aparece como marca de continuidade de práticas habitualmente empregadas. A tortura, que no regime autoritário era uma prática recorrente nos interrogatórios dos presos políticos, passou a ser um exercício frequente nas detenções e nos inquéritos envolvendo pessoas pobres, negros e desempregados.
}

Os governos democráticos enfrentam o desafio de implementar uma política de segurança pública capaz de conter a criminalidade, tendo como referência os princípios do Estado de Direito.

Geraldo Prado (2013; p. 32-33), ao falar sobre a transição democrática no sistema de justiça criminal afirma que "a democracia política até o momento não deu conta das demandas de universalização do respeito à dignidade da pessoa humana, desafio que requisita mudanças profundas no aparato repressivo do próprio sistema, mas também na formação dos juristas".

Geraldo Prado (2013; p. 38), examinando o funcionamento da justiça penal durante os regimes autoritários brasileiros no século XX (1937-45 e 1964-85), afirma que:

\footnotetext{
As justiças penais funcionaram regularmente, mesmo em seguida aos golpes de estado, e foram também funcionais aos novos regimes autoritários, incrementando e conferindo às práticas violadoras da dignidade das pessoas o selo de juridicidade que, aparentemente, inscrevia tais práticas em um contexto de "normalidade institucional".
}

Exemplo disso é ausência quase absoluta de censura social ao emprego da tortura, tolerada em um nível de naturalização da violência que ainda hoje contamina o aparato estatal da repressão.

\footnotetext{
8 A propósito veja-se a entrevista de Zaffaroni: "A esquerda tem medo, não tem política pública de segurança”. Revista brasileira de segurança pública, ano 1, edição 1, 2007, disponível em: revista.forumseguranca.org.br, Acesso em: 13 dez. 2015.
} 
A doutrina processual penal, por sua vez, raramente interessou-se em investigar as origens do nosso modelo judiciário penal.

Neste cenário, as garantias do devido processo inexistem para a maioria da população, em particular para os afro-latinos, os indígenas, as meninas, as crianças, os adolescentes, LGBT. (PRADO: 2013; p. 40)

As práticas policias, por sua vez, igualmente, ainda não se submeteram ao programa democrático instituído pela Constituição de 1988. Não são, no dizer de Cláudio Pereira de Souza Neto, "práticas constitucionalizadas, comprometidas com a construção de uma república de cidadãos livres e iguais e com a promoção da dignidade da pessoa humana".

O Relatório sobre Execuções Sumárias no Brasil (1997-2003) aponta que "episódios internacionalmente conhecidos, como Eldorado dos Carajás, Candelária, Carandiru, Corumbiara e Favela Naval são expressões máximas de uma sistemática prática de extermínio e opressão perpetrada diariamente, direta ou indiretamente, por agentes do Estado em praticamente todo o território nacional". No período investigado, 349 execuções foram detectadas e "seguem padrão de extermínio e impunidade a quem tortura, fere e mata". (PRADO: 2013; p. 41-42)

\section{A NECESSIDADE DE MUDANÇA DE PARADIGMA NA SEGURANÇA PÚBLICA}

Para o desenvolvimento da segurança pública, é preciso uma mudança do paradigma repressivo que comanda as ações da área há séculos. Segundo Vera Regina Pereira de Andrade (2015, online), para ultrapassar o paradigma repressivo em segurança pública é necessário, em nível ideológico e simbólico, ultrapassar e redefinir os conceitos fundamentais e o senso comum que lhe dão sustentação: criminalidade (identificada com criminalidade de rua e da pobreza), violência (identificada com esta criminalidade) e segurança pública (identificada com segurança contra esta criminalidade).

Segundo Vera Regina Pereira de Andrade:

Para que a própria mudança preconizada ocorra, o princípio vertebral a sustentar todos os demais deve ser o princípio de proteção integral de direitos humanos, erigido como o objeto e limite do poder de punir e no qual o direito à segurança (sobretudo a segurança da pessoa, da vida e dos corpos, antes que dos bens) seja um deles, libertando-se do paradigma da segurança "contra" a criminalidade. Isso faz a passagem do modelo de segurança pública focado na ordem e em nome da ordem, violando seletivamente direitos da pessoa, para um modelo de segurança pública focado no sujeito - segurança cidadã; faz ainda a passagem do paradigma repressivo (negativo e desconstrutor) de luta contra a criminalidade para uma cultura positiva e construtora de uma nova concepção de segurança e controle democrático dos problemas e conflitos sociais. (BARATTA, 1987, 1997, 2000; SABADELL: 2003; 1-28)

Conforme entendimento de Lúcia Lemos Dias (2010; p. 72-73):

A política de Segurança Pública deve ser configurada como política pública (social) incorporando, também, as necessidades de segurança dos grupos socialmente vulneráveis, devendo contemplar as várias dimensões dos direitos. Ou seja, ela deve apresentar-se de forma democrática, perpassando pelos Direitos Humanos, direitos civis, políticos, econômicos e sócio-culturais de forma indissociável, em conformidade com o modelo de Estado democrático de direito. 
Para adequar a noção de segurança pública ao Estado democrático de direito, no mínimo deve ser revista a discussão sobre ordem pública e a relação indistinta que tem sido feita entre ordem e segurança.

O objetivo primordial do Estado democrático de direito é a promoção do bem-estar social da coletividade. Assim, a ordem pública não pode estar dissociada dos direitos humanos, conforme assim corrobora Hermano Vallencia Villa, citado por Lúcia Lemos Dias (2010; p. 73-74), que define a ordem pública como:

Conjunto de condições materiais necessárias e suficientes para o bom funcionamento da sociedade, de tal modo que o exercício da autoridade do Estado assegure a prática dos Direitos Humanos dos cidadãos em circunstância de conflito e crise.

O processo civilizacional em curso nesse início de século XXI impõe aos Estados contemporâneos a necessidade de conceber a segurança como garantia do exercício da cidadania.

Conforme Vilobaldo Adelídio Carvalho e Maria do Rosário de Fátima e Silva (2011; p. 60):

A política de segurança pública pode ser definida como a forma de instituir mecanismos e estratégias de controle social e enfrentamento da violência e da criminalidade, racionalizando as ferramentas da punição (...) ou seja conjunto de ações delineadas em planos e programas e implementados como forma de garantir a segurança individual e coletiva.

Laércio Noronha Xavier (2012; p. 21) em "Políticas Públicas de Segurança”, por sua vez, esclarece:

\begin{abstract}
A concepção tradicional de Políticas de Segurança Pública vem sendo substituída, paulatinamente, pela nova terminologia conceitual Políticas Públicas de Segurança, com diferentes experiências municipais, nacionais e internacionais, provando que as questões de Segurança Pública não são problemas exclusivamente da "polícia". Para a nova concepção, a promoção de uma Segurança Pública moderna, eficiente e democrática requer, além da participação do ente estadual, responsável direto por tal política, a modificação na organização e nas ações do ente federal e a responsabilidade da municipalidade no planejamento, definição e implementação de diferentes políticas públicas de caráter preventivo, organizacional, estrutural e transformador. As Políticas Públicas de Segurança necessitam, ainda, da participação contínua dos cidadãos, engajamento das entidades sociais, envolvimento da iniciativa privada e aparato técnico de múltiplos profissionais.
\end{abstract}

Infelizmente, ainda são incipientes as iniciativas para a democratização da segurança pública e construção de políticas públicas de segurança. Para isso, é necessário que se consiga tratar a segurança como uma política pública, e não apenas como uma política de governo, sendo imprescindível o planejamento estatal no setor.

\title{
6 AS INICIATIVAS PARAA DEMOCRATIZAÇÃO DA SEGURANÇA PÚBLICA
}

A segurança pública no Brasil, historicamente tratada como "coisa de polícia”, foi tardiamente inserida no contexto das políticas sociais. (SOUZA; 2015) 
Nos governos FHC e Lula, saímos de uma política num viés essencialmente policial e repressivo para a gradual construção de um novo modelo, na tentativa de posicionar a segurança pública como fundamento para a realização dos direitos de cidadania, onde a União resolveu assumir um papel de indução e centralidade dessa política.

No Governo FHC (1995-1998 e 1999-2002), uma nova política de segurança pública foi se institucionalizando. Nesse período, foi instituído o Programa Nacional de Direitos Humanos (1996), a Secretaria Nacional de Direitos Humanos e a Secretaria Nacional de Segurança Pública (1997).

No ano de 2000, instituiu-se o primeiro Plano Nacional de Segurança Pública, elaborado às pressas, depois do sequestro do ônibus 174 , no Rio de Janeiro. O país assistiu pela TV, com perplexidade, aquela tragédia. O Presidente da República Fernando Henrique Cardoso determinou que se tirasse da gaveta o plano que vinha sendo gestado em seu governo, por sucessivos Ministros da Justiça. Em uma semana foi apresentado à nação o primeiro plano de segurança pública de sua história. No entanto, segundo afirma Luiz Eduardo Soares, "o documento apresentado à nação como um plano não atendia aos requisitos mínimos que o tornassem digno daquele nome". (SOARES: 2012; online)

O Plano, todavia, apresenta uma inovação fundamental ao voltar-se para a promoção, garantia e efetividade dos direitos humanos e ao apoiar programas de prevenção à violência, visando recuperar o controle estatal do crime e da violência. A promoção da cidadania e a efetividade dos direitos humanos e da segurança pública começa a pautar os debates nacionais.

Conforme mostra Robson Sávio Reis Souza, no que tange à política nacional de segurança pública, passamos por uma mudança discursiva, pois, no governo FHC, passamos de um modelo de segurança pública militarizado para um modelo civil. Já no Governo Lula, houve nova tentativa de mudança: de um modelo de segurança pública civil para o modelo de segurança pública cidadã que, porém, resultou fracassada.

No Governo Lula (2003-2006 e 2007-2010), a política de segurança pública começou a ser traçada a partir do Projeto de Segurança Pública para o Brasil, elaborado pela ONG Instituto da Cidadania, que serviu de base para o programa de governo na disputa eleitoral de 2002. Em 2007, foi estruturado o Plano Nacional de Segurança Pública com Cidadania (Pronasci), cujo foco, conforme aponta Robson Sávio (SOUZA: 2015; p.132), era a promoção dos direitos humanos, tendo como fulcro o conceito de "segurança cidadã", intensificando uma cultura de paz, de apoio ao desarmamento e de combate sistemático aos preconceitos, assim como a valorização dos profissionais de segurança pública e programas para os jovens de 15 a 24 anos (faixa etária com maior índice de homicídios).

Em 2009, foi realizada a $1^{\text {a }}$ Conferência Nacional de Segurança Pública (CONSEG), precedida de cerca de 500 audiências públicas em diversos municípios. Pela primeira vez se realizou um amplo debate acerca do modelo de segurança pública a ser implementado no país.

Porém, no turbilhão de confronto entre o velho e o novo, ou seja, no embate entre os que defendem mudanças estruturais na política de segurança pública e os que defendem a manutenção do atual modelo, observou-se um recrudescimento de setores ligados à coalizão conservadora, obstaculizando novos avanços na política. Terminada a Conferência, no embate entre os vários atores 
que disputam o domínio da política nacional de segurança pública, não foi possível a construção de consensos e deliberações políticas capazes de alterar o quadro institucional, restando a postura de imobilismo do Ministério da Justiça (lastreada no discurso segundo o qual não havia condições políticas para avanços), o conformismo vitorioso e meio envergonhado dos setores que mantiveram seu status quo intocado e a decepção daqueles que esperavam por mudanças. (SOUZA: 2015; p. 301)

No primeiro mandato de Dilma Rousseff (2011-2014) observa-se um quadro institucional sem grandes alterações, uma agenda paralisante e sem mudança substantivas, que perdurou todo período. Na disputa eleitoral de 2014, Dilma Rousseff foi vitoriosa sem apresentar um programa de segurança pública à população, apesar do quadro de violência endêmica que persiste no Brasil. $\mathrm{O}$ governo começou sem uma agenda definida para a segurança pública e o discurso do Estado penal voltou com toda força.

O Governo Temer criou o Ministério da Segurança Pública pela Lei 13.690/2018. Em 11 de junho de 2018, o Governo Temer sancionou a Lei $n^{\circ} 13.675$, que criou a Política Nacional de Segurança Pública e Defesa Social (PNSPDS) e instituiu o Sistema Único de Segurança Pública (Susp). Em dezembro de 2018, o Governo Temer publicou um Plano e Política Nacional de Segurança Pública e Defesa Social (SEGURANÇA: 2018; online), instituído pelo Decreto ${ }^{\circ}$ 9.630/2018.

O Governo Bolsonaro reunificou o Ministério da Justiça e Segurança Pública, por meio da Medida Provisória $n^{\circ} 870$, de $1^{\circ}$ de janeiro de 2019. O Ministro da Justiça encaminhou ao Congresso Nacional um "Pacote Anticrime"(JUSTIÇA: 2019; online) contendo alterações em diversos dispositivos legais em vigor, com o objetivo de elevar penas, mitigar os direitos e garantias constitucionais, endurecer o cumprimento das penas e introduzir soluções negociadas no Código de Processo Penal e na Lei de Improbidade Administrativa. O Pacote Anticrime amplia as hipóteses de exclusão da antijuridicidade das ações policiais violentas, o que coloca o país no caminho inverso da construção de uma política pública de segurança, condizente com as diretrizes legais que devem reger o sistema de segurança pública no Estado democrático de direito.

\section{CONCLUSÃO}

A questão da segurança pública tem despertado a atenção e o interesse de vários pesquisadores, da sociedade e do governo.

Para além de problematizar a construção do sistema nacional de segurança pública, este artigo buscou analisar os caminhos que foram e estão sendo percorridos, além de esclarecer a complexidade dos discursos e dos pressupostos ideológicos sob os quais se assentam os conceitos de segurança pública e defesa social, no contexto do sistema penal, dicotomizado entre o punitivismo e a necessidade de novos rumos que levem em conta os estudos para a contenção da violência por meio de políticas públicas.

Reduzir a criminalidade respeitando as regras do estado democrático de direito é o grande desafio. As forças de segurança pública ainda não se adequaram à Constituição Federal de 1988, 
no que diz respeito à dignidade da pessoa humana, obediência à legalidade democrática e respeito às liberdades públicas.

O paradigma dominante ainda é o da guerra ao crime e combate ao criminoso. Ocorre que a lógica da guerra é comandada pela busca da eliminação do inimigo, a quem não se deve reconhecer direitos. A decorrência desse sistema de crenças é a barbárie policial e o arbítrio da justiça penal.

A concepção de segurança pública é vital para o debate sobre como reduzir a violência no Estado Democrático de Direito. Neste viés, entendemos que a política de segurança pública deve ser substituída, ou gradualmente transformada, em política pública de segurança apta a promover, não somente (ou principalmente) a ordem pública, mas sobretudo a segurança humana, respeitando-se e assegurando todos os direitos de todas as pessoas.

Por sua vez, a defesa social deve ser entendida como a defesa de todas as pessoas e não a defesa do Estado, nem de uma determinada classe social ou de um grupo de pessoas em detrimento de outros. Para isso, é preciso que haja normas técnicas, regras de conduta e padrões operacionais que implementem uma nova cultura organizacional e de gestão da atividade policial.

\section{REFERÊNCIAS}

ANDRADE, Vera Regina Pereira de. A mudança do paradigma repressivo em Segurança Pública: reflexões criminológicas críticas em torno da proposta da $1^{\text {a }}$ Conferência Nacional Brasileira de Segurança Pública. Disponível em http://www.scielo.br/pdf/seq/n67/13.pdf, Acesso em: 24 jul.2015.

ANCEL, Marc. A nova defesa social: Um movimento de Política Criminal humanista. Rio de Janeiro: Forense, 1979.

ARAÚJO JÚNIOR, João Marcelo. Sistema Penal para o Terceiro Milênio: atos do Colóquio Marc Ancel. 2 ed. Rio de Janeiro: Revan, 1991.

AZEVEDO, Noé. As garantias da liberdade individual em face das novas tendências penais. In: Teodolindo Castiglione. Lombroso perante a criminologia contemporânea. São Paulo: Saraiva, 1936.

CERQUEIRA, Daniel; LOBÃO, W. Condicionantes sociais, poder de polícia e o setor de produção criminal. Rio de Janeiro: Ipea, 2003 (Texto para Discussão, 957).

; LOBÃO, Waldir; CARVALHO, Alexandre. O jogo dos sete mitos e a miséria da segurança

pública no Brasil. Rio de Janeiro: Ipea, 2005. (Texto para discussão, $\mathrm{n}^{\circ}$ 1144). Disponível em http://www. ipea.gov.br/portal/images/stories/PDFs/TDs/td_1144.pdf>. Acesso em: 30 nov. 2015.

DIAS, Lúcia Lemos. A política de segurança pública entre o monopólio legítimo da força e os direitos humanos. Tese apresentada ao Programa de Doutorado em Serviço Social. Recife: UFPE, 2010.

FREITAS, Wagner Cinelli de Paula. Espaço urbano e criminalidade: Lições da escola de Chicago. São Paulo: IBCCRIM, 2002.

FOUCAULT, Michel. Vigiar e punir: história da violência nas prisões. Petrópolis: Vozes, 1983.

Em defesa da sociedade. São Paulo: Martins Fontes, 2005.

LIMA, Renato Sérgio de.; RATTON, José Luiz; AZEVEDO, Rodrigo Ghinringhelli de. Crime, polícia e justiça no Brasil. São Paulo: Contexto, 2014.

Contexto, 2008.

; e outros. Segurança Pública e violência: o Estado está cumprindo o seu papel? São Paulo:

. Et all. Segurança pública e violência. São Paulo: contexto, 2008.

; BUENO, Samira (Orgs). Polícia e democracia: 30 anos de estranhamentos e esperanças. São 
Paulo: Alameda, 2015.

MINGARDI, Guaraci. Política de segurança: os desafios de uma reforma. São Paulo: Perseu Abramo, 2013.

SANTOS, Altamiro J. dos. Direito de segurança pública e legítima defesa social. São Paulo: LTR, 2006. SANTOS, Bartira Macedo de. Defesa social: uma visão crítica. São Paulo: Estúdio Editores.com, 2015.

SOUZA NETO, Cláudio Pereira de. A segurança pública na Constituição Federal de 1988: conceituação constitucionalmente adequada, competências federativas e órgãos de execução das políticas. Revista Diálogo Jurídico, $\mathrm{n}^{\circ}$ 17, 2008.

SOUZA, Robson Sávio Reis. Quem comanda a segurança pública no Brasil?: atores, crenças e coalizões que dominam a política nacional de segurança pública. Belo Horizonte: Letramento, 2015.

SULOCKI, Victoria-Amália de Barros Carvalho G. de. Segurança Pública e Democracia: aspectos constitucionais das políticas públicas de segurança. Rio de Janeiro: Lumen Juris, 2007.

XAVIER, Laércio Noronha. Políticas Públicas de Segurança. Fortaleza: LCZ, 2012.

ZAFARONI, Eugênio Raúl. A questão criminal. Rio de Janeiro: Revan, 2013.

; OLIVEIRA, Edmundo. Criminologia e Política Criminal. Rio de Janeiro: GZ, 2010.

. A esquerda tem medo, não tem política pública de segurança. Revista Brasileira de Segurança

Pública, ano 1, edição 1, 2007, Disponível em: revista.forumseguranca.org.br, Acesso em: 13 dez. 2015.

Data de submissão do artigo: Dezembro de 2019

Data de aceite do artigo: Março de 2020(*)

(*) NOTA TÉCNICA:

Esclarecemos que, em razão do ataque de hackers a que foi submetido o conjunto de periódicos da Universidade Federal de Goiás (UFG), ao que se inclui a Revista da Faculdade de Direito da UFG (RFD/UFG), os artigos ordenados entre os números 21-30, referentes ao volume 43, embora tenham sido recebidos e aceitos em datas distintas e anteriores, dado o perecimento de suas referências, foram todos registrados com o expediente de aceite no mês de março de 2020. 